\title{
CMS-ASSISTED ROCK MASS STABILITY ASSESSMENT FOR UNDERGROUND EXCAVATION
}

\author{
H. LU ${ }^{1,2}$, Z.Q. LUO ${ }^{1} \&$ M. MOMAYEZ ${ }^{2}$ \\ ${ }^{1}$ School of Resources and Safety Engineering, Central South University, People's Republic of China. \\ ${ }^{2}$ Department of Mining \& Geological Engineering, University of Arizona, USA.
}

\begin{abstract}
The accurate shape and position of cavities in an underground mine are important factors that could affect the reliability of numerical modeling analysis result. The traditional numerical stability analysis of underground mined out stopes either considers the cavity shape as a regular geometric object or uses a simple model created for analysis purposes; both of the methods could affect the accuracy of numerical simulation results. Cavity monitoring system (CMS) is used to survey the actual 3D shape and the true position of the cavities. The 3D digital terrain model (DTM) of the grouped cavities is then created in the mine design software. A novel and integrated approach to access the stability of the underground cavity based on the DTM and numerical models is presented. By following a planned excavation sequence, the in situ stress distribution condition of the mining area has been assessed. The result will be considered as the basis of the excavation re-arrangement and safety strategy of the mining area. Keywords: CMS, FLAC, mining cavity, numerical simulation, rock mass, safety \& stability.
\end{abstract}

\section{INTRODUCTION}

The actual shape of an underground opening is usually irregular due to the impact of blasting. The numerical analysis model with accurate cavity contour and position is typically not available. Cavity monitoring system (CMS) is an efficient device to survey the 3D shape of mined out opening. The CMS by Optech is a 3D laser scanner, which can draw the $3 \mathrm{D}$ contour and provide the position of cavities fast and precisely in underground mine. Figure 1 shows the scanning principle of CMS. The scanner has a $360^{\circ}$ horizontal and $290^{\circ}$ vertical field of view, with an angular accuracy and resolution of 0.1 and 0.022 , respectively, a range accuracy and resolution of $2 \mathrm{~cm}$ and $1 \mathrm{~mm}$, respectively, and samples of 52,200 points per scan. The construction of three-dimensional digital terrain model (DTM), block model and rock layers all are based on the CMS surveyed information; Surpac and FLAC ${ }^{3 \mathrm{D}}$ are chosen to be the modeling and numerical analysis software. The surveyed data must be readable by the modeling software and the DTM model, which contains key information that will be transferred from DTM to numerical analysis model. The new approach to solve the model conversion problem is called coupled method, and it is quite fast and reliable. After the data acquisition, modeling and conversion, the numerical simulation and rock mass stability assessment work are performed. The case study is a copper mine with a depth of $800 \mathrm{~m}$. Simulate the stress condition by following the planed excavation sequence and assess the quality of each step. The result will be the reference for the excavation sequence, optimize, and rearrangement.

\section{NUMERICAL MODELING APPROACH}

Preprocessing of data in FLAC ${ }^{3 \mathrm{D}}$ needs quite a lot workload and it is not particularly suitable for building a complex geological model. The mine planning software Surpac, however, has a module to build a comprehensive 3D block model. Both of the software packages can handle block models made of multi-grid cells. This feature allows the exchange of block model data between Surpac and FLAC ${ }^{3 D}$. By coupling the advanced geologic modeling capabilities 
of Surpac and the greater computational feature of FLAC $^{3 \mathrm{D}}$, the numerical analysis process can be optimized and the accuracy of simulation result can be improved [1-4]. Figure 1 shows the flow chart of the proposed numerical analysis process.

\subsection{Complex geological modeling}

To create a FLAC ${ }^{3 \mathrm{D}}$ readable model from Surpac, the following procedure is proposed:

1. Build the digital elevation model (DEM) of the ground surface of the overall mining area, rock layers, and underground openings. The DEM and DTM models are built by referencing cross-section data saved in DXF file. The DTM of the underground openings is imported directly from the CMS hardware into Surpac, where the actual 3D shape and location of the mined out cavities are displayed accurately.

2. Verify block model parameters, such as coordinates, scale, azimuth, dip, and the size of each cell. The scale model created in Surpac provides the coordinates of the initial model. The selection of the azimuth and dip must be carried out in such a way that they are conveniently implemented in FLAC ${ }^{3 \mathrm{D}}$. The geological model must be parallel to the $X-Y$ plane. Therefore, the azimuth and dip are set to zero. The selection of the size of the element in general depends on the purpose of the model; for example, a smaller element size around the edges of the cavity will improve the accuracy of the contour, while larger elements elsewhere will improve the speed of the calculations. This approach is used to pick parameters, build the block model and achieve the element partition.

3. Export the model from Surpac into a data file.

4. Process and transform the output data into the format readable FLAC ${ }^{3 \mathrm{D}}$.

5. Import the file into FLAC ${ }^{3 \mathrm{D}}$ to conduct the geomechanical simulation.

6. Use the rock mass DTM model and the cavity DTM model, which have been built to create the rock type layers and the cavity constraint parameter file, respectively, to assign values to the elements and complete the construction of the complex geological model [3].

\subsection{Model conversion}

STEP 1: To import the geological block model from Surpac into FLAC ${ }^{3 \mathrm{D}}$, the element data stored in Surpac must be transformed into a FLAC ${ }^{3 D}$ specific format. The shape of the element is a regular hexahedron, where $X, Y$ and $Z$ are the element centroid coordinates;

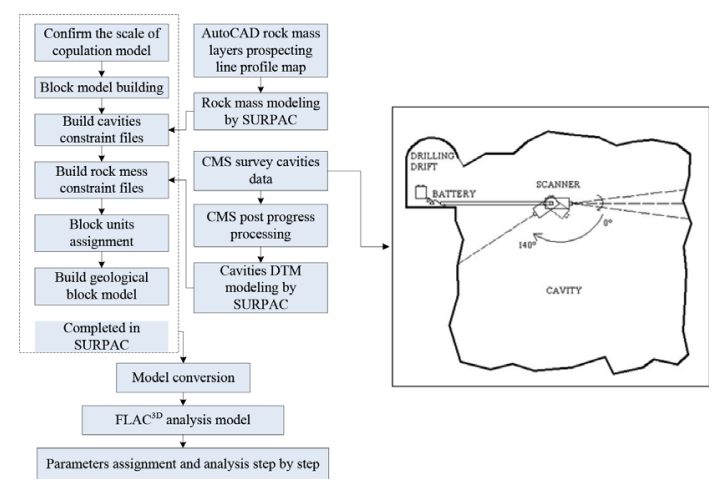

Figure 1: Coupled-model flow chart. 
$\operatorname{SIZE}(X), \operatorname{SIZE}(Y)$ and $\operatorname{SIZE}(Z)$ are the length of the edges, while the remaining entries in the table are the attributes of the rock mass parameters.

STEP 2: Use an 8-node brick as the element unit. The coordinate $(X, Y, Z)$ will be the center of the element and the coordinates of P1-P8 are obtained from $\operatorname{SIZE}(X), \operatorname{SIZE}(Y)$ and $\operatorname{SIZE}(Z)$. The input parameters are listed in Table 1.

STEP 3: The entire model will then be divided into separate layers based on the rock parameter attributes obtained from drilling data. The layers are built into the DTM and constraint values are assigned. Ten layers were built in this case.

STEP 4: Export the Surpac block model elements into a spreadsheet. A preprocessing program is developed to transform the .xls format file into a .dat command flow file, which is recognizable by FLAC $^{3 \mathrm{D}}[5,6]$. The conversion process is as follows:

1. In the output data file, the coordinates of the centroid (center point) of each element is added or subtracted by half of the length of each edge element to obtain the coordinates of each node element (eight in total). Store the $X, Y, Z$ coordinates of each of the P1, P2, P3, P4, P5, P6, P7, P8 nodes in the .dat file.

2. Identify and arrange all the nodes. The command is 'Generate $\mathrm{n} \mathrm{x} 1, \mathrm{y} 1, \mathrm{z} 1$ ', where ' $n$ ' is the identification number of the node.

3. Repeat the above step for the brick nodes using the command 'Generate Zone Brick P1 x1,y1,z1 P2 x2, y2, zl P3 x3, y3, z3 P4 x4, y4, z4 size n1, n2, n3', 'ZoneBrick8m, n1, n2, $\mathrm{n} 3, \mathrm{n} 4, \mathrm{n} 5, \mathrm{n} 6, \mathrm{n} 7, \mathrm{n} 8$ ', where ' $\mathrm{m}$ ' is the identification number of the element.

4. Group the elements based on whether the element belongs to a cavity or not using the command: 'Zone Group <name $>$ m', where the 'name' is the name of cavity and ' $m$ ' is still the identification number of the element.

5. Each element in FLAC ${ }^{3 \mathrm{D}}$ can only belong to one group, whereas in Surpac one element can be a member of two groups. During the conversion, determine the group's information subject to which cavity the element belongs to. Record the group information in the command flow file.

6. Use the command 'Property $<$ mechanics parameters $>$ Rang m' to assign the parameters into the model.

STEP 5: Finish model conversion and import it into FLAC ${ }^{3 \mathrm{D}}$ :

Group the elements in the same cavity by following STEP 4: Run the dat command flow file by the 'call' function in FLAC ${ }^{3 \mathrm{D}}$ (see Fig. 2).

Table 1: Element information of Surpac block model.

\begin{tabular}{|c|c|c|c|c|c|c|c|}
\hline$X Y Z \operatorname{SIZE}(X)$ & $\operatorname{SIZE}(Y)$ & $\operatorname{SIZE}(Z)$ & $\begin{array}{l}\text { Types of } \\
\text { the ore } \\
\text { and rock }\end{array}$ & $\begin{array}{l}\text { Specific } \\
\text { gravity }\end{array}$ & $\begin{array}{l}\text { Modulus } \\
\text { of } \\
\text { elasticity }\end{array}$ & $\begin{array}{l}\text { Internal } \\
\text { friction } \\
\text { angle }\end{array}$ & $\begin{array}{l}\text { Cohesive } \\
\text { force }\end{array}$ \\
\hline
\end{tabular}

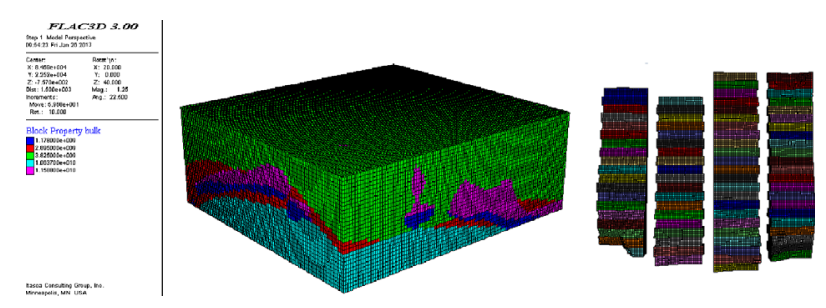

Figure 2: FLAC $^{3 \mathrm{D}}$ numerical simulation calculation model. 


\subsection{Brick primitive shapes}

\section{NUMERICAL ANALYSIS}

Assume the ore rock mass as a continuous, homogeneous and elastic material. Fix the displacement in the $\mathrm{X}$ and $\mathrm{Y}$ directions and set the top surface to carry no load. In the present model, there are a total of 318,630 elements and 331,936 nodes.

To simplify model exchange between Surpac and FLAC ${ }^{3 \mathrm{D}}$, a unit cube mesh element with eight nodes (see Fig. 3) is selected [7].

Description of the element geometry: $q e$ is the nodal displacement and $P e^{\text {the }}$ nodal forces.

$$
\begin{gathered}
q^{e}=\left[\begin{array}{llll}
u_{1} v_{1} w_{1} u_{2} v_{2} w_{2} & \cdots & u_{8} v_{8} w_{8}
\end{array}\right]^{T}, \\
P^{e}=\left[\begin{array}{llll}
P_{x 1} P_{y 1} P_{z 1} P_{x 2} P_{y 2} P_{z 2} & \cdots & P_{x 8} P_{y 8} P_{z 8}
\end{array}\right]^{T}
\end{gathered}
$$

For the 8-node brick element, assume that it is homogeneous over an infinitesimally small element of a finite unit. To find the components of the matrices, consider the eight nodes of a hexahedron as variables (see Fig. 3). The related matrices in an analogous fashion to the finite case are presented by eqns (1) and (2)

$$
\left\{\begin{array}{l}
u(x, y, z)=a_{1}+a_{2} x+a_{3} y+a_{4} z+a_{5} x y+a_{6} y z+a_{7} z x+a_{8} x y z \\
v(\mathrm{x}, \mathrm{y}, \mathrm{z})=b_{1}+b_{2} x+b_{3} y+b_{4} z+b_{5} x y+b_{6} y z+b_{7} z x+b_{8} x y z \\
w(\mathrm{x}, \mathrm{y}, \mathrm{z})=c_{1}+c_{2} x+c_{3} y+c_{4} z+c_{5} x y+c_{6} y z+c_{7} z x+c_{8} x y z
\end{array}\right.
$$

To calculate the unknown coefficients $a_{1}, a_{2}, \ldots, b_{1}, b_{2}, \ldots, c_{1}, c_{2}, \ldots, c_{8}$, in eqn (3), substitute into eqn (4) to get the shape function matrix of the element

$\mathrm{u}=\left[\begin{array}{c}u \\ v \\ w\end{array}\right]=\left[\begin{array}{cccccccccc}N_{1} & 0 & 0 & N_{2} & 0 & 0 & \cdots & N_{8} & 0 & 0 \\ 0 & N_{1} & 0 & 0 & N_{2} & 0 & \cdots & 0 & N_{8} & 0 \\ 0 & 0 & N_{1} & 0 & 0 & N_{2} & \cdots & 0 & 0 & N_{8}\end{array}\right] v q^{e}=N^{e} v q^{e} .(4)$

The geometric matrix, stiffness matrix, nodal equivalent load matrix and stiffness equation are computed using algorithms developed for finite element analysis once the shape function matrix for the unit element is obtained.

Geometric matrix:

$$
\stackrel{\circ}{\mathrm{a}}=[\partial] u=[\partial] N^{e} Q^{e}=B^{e} q^{e}
$$

Stiffness matrix:

$$
K^{e}=\int_{\Omega^{e}} B^{e^{T}} D^{e} B^{e} \mathrm{dU}
$$

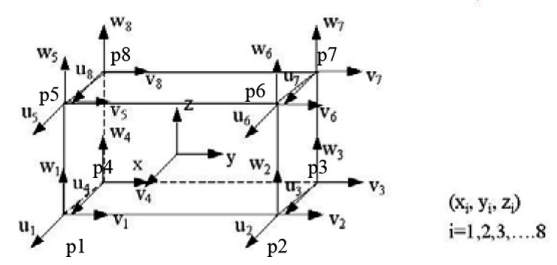

Figure 3: Schematic diagram of a cubic mesh element. 
Nodal equivalent load matrix:

$$
P^{e}=\int_{\Omega^{e}} N^{e^{T}} \bar{b} \grave{\mathrm{Ud}}+\int_{S_{p}^{e}} N^{e^{T}} \overline{\mathrm{d}} p s .
$$

Stiffness equation:

$$
K_{(24 \times 24)}^{e} q_{(24 \times 1)}^{e}=P_{(24 \times 1)}^{e}
$$

3.2 Simulation configuration and parameters

The rock mass of the case copper mine includes diorite, marble, serpentine, magnetite copper and so on. They are elastic-plastic material, so Mohr Coulomb criterion and tensile failure criteria have been selected [8-11].

Strength reduction method is referenced to build the model and process simulation. Reduction factor for internal friction angle $\phi$ is 0.85 , reduction factor of cohesion is $1 / 7$ to $1 / 10$ and reduction factor for the elastic modulus is $2 / 3$. Elastic modulus of backfill tailing material is $1 \mathrm{GPa}$. Mechanics parameters are in Table 2.

Since FLAC ${ }^{3 D}$ uses the bulk modulus and shear modulus to describe the elastic modulus and Poisson's ratio, therefore, conversion relationship is listed in formula

$$
\left.\begin{array}{l}
K=\frac{E}{3(1-2 v)} \\
G=\frac{E}{2(1+v)}
\end{array}\right\} .
$$

where $K$ is the bulk modulus, $G$ is the shear modulus, $E$ is the elastic modulus and $v$ is the Poisson's ratio.

\subsection{Excavation sequence arrangement}

Excavate the panel 1 and 3 first, and then panel 2. When excavating panels 1 and 3, follow the rule 'pick one every other three', and backfill them after mining out. Excavate three rooms at the same time so that in total there will be six rooms under excavation in two panels. Follow the steps show in Fig. 4 to calculate and simulate.

Table 2: Parameters of rock mass.

\begin{tabular}{lccccccc}
\hline & & & & \multicolumn{5}{c}{ TS $\sigma t$} & Cohesion \\
& $\rho\left(\mathrm{g} / \mathrm{cm}^{3}\right)$ & $K(\mathrm{GPa})$ & $G(\mathrm{GPa})$ & $v$ & $(\mathrm{MPa})$ & $C(\mathrm{MPa})$ & $\Phi\left(^{\circ}\right)$ \\
\hline Marble of Huanglong & 2.7 & 8.317 & 3.21 & 0.329 & 1.7 & 1.604 & 33.5 \\
Marble of Chihsia & 2.71 & 10.2 & 5.916 & 0.257 & 2.24 & 1.714 & 45.02 \\
Serpentine & 3.3 & 6.28 & 4.325 & 0.22 & 2.102 & 2.323 & 49.64 \\
Quartz diorite & 2.72 & 21.27 & 11.89 & 0.264 & 2.78 & 2.75 & 45.9 \\
Ore & 3.97 & 23.177 & 14.197 & 0.253 & 3.04 & 3.69 & 45.07 \\
Tailing backfill & 2 & 0.67 & 0.357 & 0.25 & - & 0.4 & 33 \\
\hline
\end{tabular}




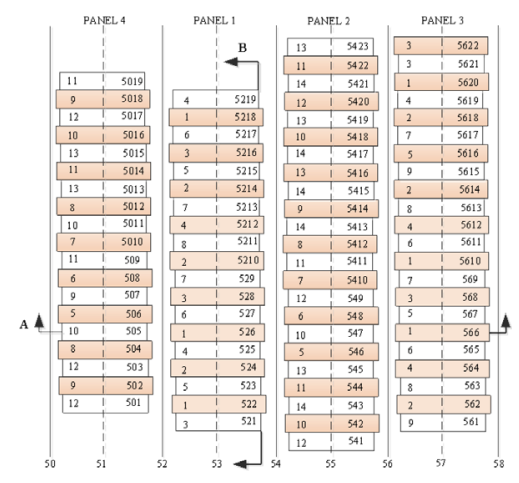

Figure 4: Horizontal layout of cavities and excavation sequence.

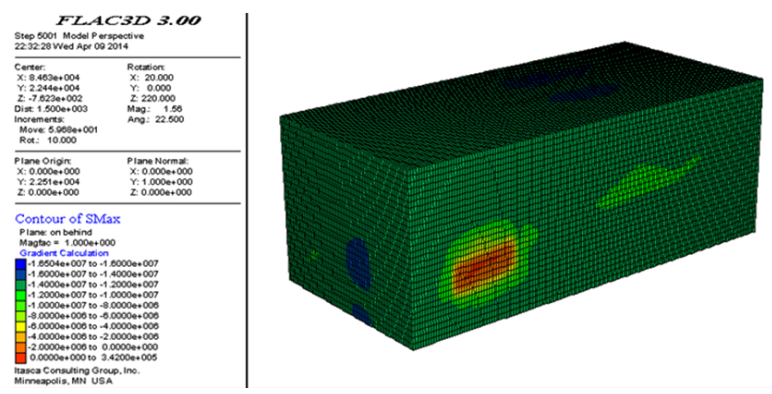

Figure 5: Contour of maximum principal stress in 3D view.

There are 14 steps in total. In step 1, excavate the rooms (522, 526, 5218, 566, 5610 and 5620 ) at panels 1 and 3. For every step, excavate the stopes in that step and backfill the stopes in the previous step. Therefore, in step 2, excavate 524, 5210, 5214, 562, 5614 and 5618 and backfill 522, 526, 5218, 566, 5610 and 5620, and by following this analogy to the other steps.

\subsection{Stress field analysis}

The maximum and minimum principal stress increased as the excavation goes on. Generally, the maximum principal stress reaches a maximum at the end of the excavation. After step 8 , the maximum principal stress at line 53 is $62.06 \mathrm{MPa}$. In panel 3, maximum principal stress reaches a maximum value of $56.37 \mathrm{MPa}$ at the end of step 9. By the influence of the excavation in panels 2 and 4, the maximum principal stress continues to increase and reach a peak of $66.70 \mathrm{MPa}$ after the excavation of panel 1. The maximum principal stress around the panels at the two sides is less than the panels in the middle, with a difference of 6-10 MPa. This means there is influence between the different panels' excavation, and the closer the distance, the greater the influence is. See Fig. 5 for the 3D vision of the maximum principal stress contour.

The maximum principal stress mainly concentrates around the two sides, bottom corners and roof of the mined out stopes. After excavation and backfilling, the maximum principal stress concentrates at the left side and corner of the panel with a maximum of $66.70 \mathrm{MPa}$. The maximum principal stress at barrier pillars mainly distribute at the two sides, roof and left. At 


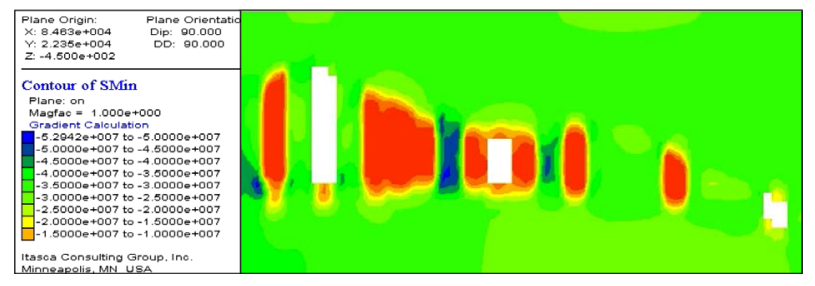

Figure 6: Maximum principal stress contours of barrier pillars along line 54 (Step 11).

Table 3: Maximum principal stress classification.

\begin{tabular}{lll}
\hline Grade & Cavity & Range \\
\hline IV & 5055011501654254754185095014501954454115422 & $60-70 \mathrm{MPa}$ \\
& 5015035017541549542050135015501954554165423 & \\
& 5435413541554175421 & \\
III & 508527521754856556115010529521356175695410504 & $50-60 \mathrm{MPa}$ \\
& 5012521154125635613502507501854145615615 & \\
II & 5215285216568562156225255212521956456125619 & $40-50 \mathrm{MPa}$ \\
& 50654652352155675616 & \\
I & 5225265218566561056205245210521456256145618 & $30-40 \mathrm{MPa}$ \\
\hline
\end{tabular}

the later period of the excavation, the maximum is moving from the middle bottom of the thicker deposit along the $\mathrm{Y}$ direction. After the overall excavation, the maximum principal stress on barrier pillars along line 54 reaches $85.29 \mathrm{MPa}$ (Fig. 6). The classification of maximum principal stress is shown in Table 3. This will reflect the overall stress distribution of each opening before backfilling. For the purpose of safety excavation, a much reasonable excavation plan or sequence can be found in reference to the classification of maximum principal stress.

The minimum principal stress reaches a peak value soon after Step 3. Minimum principal stress is mainly distributed in the bottom and top part of the mining cube, and by the extension of excavation scale, it extends to the middle also. The cross-section shows that the peak value is $16.50-16.90 \mathrm{MPa}$.

In Step 4, a peak value of tensile stress 2.22 MPa appears, and the value of other locations is less than this, and very less than the rock mass tensile strength of $3.04 \mathrm{MPa}$, theoretically that does not cause damage to the rock mass. With the backfilling of the mined out stopes, the tensile stress decreases or even disappears.

\subsection{Displacement field analysis}

The trend of displacement coincides with the maximum principal stress performance. From the cross-section of lines 53 and 57, the continuous changing appears even when the excavation is stopped. The value and scale keep extending at the top of the stopes; the shape of displacement cloud changes from points to arch, which means the displacement field is significantly affected by the maximum principal stress. From the cross-section of A-A, a maximum displacement of $25.48 \mathrm{~cm}$ appears (Fig. 7). The displacement in barrier pillar 


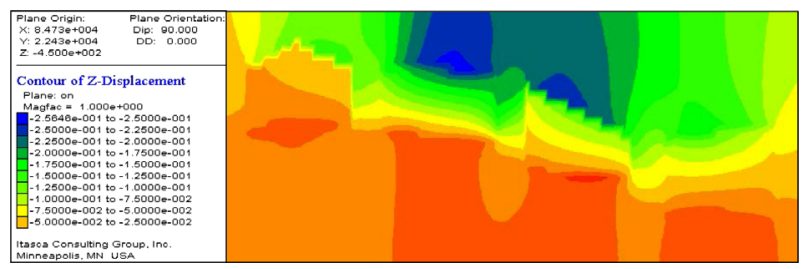

Figure 7: Vertical displacement of cross-section A-A (finished).

Table 4: Vertical displacement classification.

\begin{tabular}{lll}
\hline Grade & Cavity & Range \\
\hline IV & 5015035017541549542050135015501954554165423 & $>15 \mathrm{~cm}$ \\
& 50150350175415495420 & \\
III & 50105295213561756954105045012521154125635613 & $10-15 \mathrm{~cm}$ \\
& 502507501854145615615505501150165425475418509 & \\
& 5014501954454115422 & \\
II & 5065465235215567561650852752175485655611 & $5-10 \mathrm{~cm}$ \\
I & 5225265218566561056205245210521456256145618 & $0-5 \mathrm{~cm}$ \\
& 5215285216568562156225255212521956456125619 & \\
\hline
\end{tabular}

cross-section is smaller, $22.07 \mathrm{~cm}$, and reaches peak value at the end of excavation. Table 4 shows the classification of the vertical displacement of each opening before backfill.

For this case, by the guide of the simulation, the condition and the trend of stress, displacement and plastic zone have been calculated step by step. For each opening, the displacement, stress and plastic zone conditions have been recorded before backfilling and classified. Table 4 shows the vertical displacement of the openings before backfilling. The grade of the classification is based on the long-term mining experience of the case. The displacement of each opening before backfilling can directly reflect the roof collapse risk rate. It is more effective and direct than the maximum principal stress. Usually, fewer than $15 \mathrm{~cm}$ can be considered acceptable.

\subsection{Plastic zone analysis}

At panel 2, cross-section of line 55, the displacement zone reaches the maximum $2214 \mathrm{~m}^{2}$, mainly distribute at the sides and corners of the mined out rooms. After backfilling, plastic zone gets smaller or even disappears. Along with the cross-section A-A, after excavation the plastic zone mainly distributes at the barrier pillar between the panels. Most of the plastic zone areas locate along the line 54; after excavation, the cross-section B-B has the plastic area $6264 \mathrm{~m}^{2}$, and barrier pillar along line 54 is $5292 \mathrm{~m}^{2}$ (Fig. 8). This will affect the stability of the excavation around barrier pillars. The necessary support is needed to guarantee the safety and stability of the drift.

The effect of excavating an opening on the surrounding rock mass is a nonlinear and irreversible process. In situ (virgin) stresses are redistributed until a new equilibrium is reached. This process causes radial stresses to be removed while tangential stresses are increased. Stresses induced around openings also change in time over the long-term when secondary deformation and cracks develop in the surrounding rock mass. 


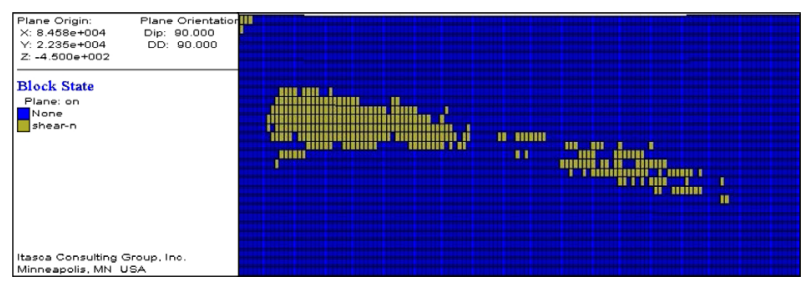

Figure 8: Plastic zone of barrier pillars along line 54 (finished).

\subsection{Suggestion}

After the simulation and classification, a suggested excavation rule can be concluded as follows. On the vertical direction of the deposit, basically push forward from anticline axis to the two flanks. On the direction of deposit inside each panel push forward from middle to the two sides. For the overall mining area, take four panels as a unit and excavated two in interval at the same time. Arrange three stopes in one panel and backfill them before next step. And excavate the other two panels after the first two are finished. This will balance the insufficient of the tailing backfill. And six stopes have production at the same time to guarantee the ability of 10,000 tons per ore day.

\section{CONCLUSIONS}

To aim at the complex geological conditions of the deep underground mine, consider the rock mass stability, safety excavation and production capacity to carry out numerical simulation for each step.

An accurate 3D scanning approach (CMS) of all the cavities is performed and the actual contour and spatial shape has been obtained. This approach provides more reliable results compared with the traditional methods, which consider the shape of the cavity as a regular geometric object and the numerical simulation model will conclude those information.

The 3D digital mining software Surpac has been used to build the block model of the mining area, which concludes all the geological information and cavities. And through a coupled approach to successfully convert the block model into an FLAC ${ }^{3 \mathrm{D}}$ numerical finite element mechanical model, the brick primitive shapes element is illustrated and introduced. In the process of transforming Surpac geologic model into FLAC ${ }^{3 \mathrm{D}}$, it is important to keep the shape of the unit element invariant. Compared with the traditional method, this approach significantly reduced the modeling workload and improved the accuracy of the calculation results. The simulation results and the key indicators classification show that: (1) excavate the panels in interval and excavate one of every other three in an effective way to avoid the over-concentration of the stress and displacement. This is good for the stability of the excavation. (2) From the stress field, the stress concentration area is expanded as the excavation continues, the maximum principal stress increases, too. The minimum principal stress appears smaller than the tensile strength of the ore and the tensile stress may disappear after backfilling, so it could consider being a good indicator to identify the failure of the rock mass. (3) From the displacement field and classification, as the excavation goes on, the maximum displacement value increases, basically same as the maximum principal stress changing trend. For the stopes that excavated afterword, the displacement is greater than the previous panels. (4) From the trend of plastic zone, plastic zone on panel barrier pillar expanded with the excavation going on, the most area on barrier pillar is in plastic zone. And with the backfilling, the plastic zone shrinks or even disappears. 
The proposed method has the potential to make underground mines safer by providing a tool that identifies areas of potential instability (rock fall and failure), and to contribute to an improved mine planning, management and decision support system. By numerical simulation analysis and some key indicators classification, the suggested rules for the case copper mine are proposed.

\section{ACKNOWLEDGMENT}

The authors thank the engineers at the Dongguashan copper mine for their assistance during site visits and providing technical information used in this study.

\section{REFERENCES}

[1] Luo, Z., Wu, Y., Liu, X., Wang-ping, L. \& Biao, Y., FLAC ${ }^{3 \mathrm{D}}$ modeling for complex geologic body based on Surpac. Rock and Soil Mechanics (in Chinese), 29(5), pp. 1134-1138, 2008.

[2] Luo, Z., Liu, X., Zhang, B., Lu, H. \& Li, C., Cavity 3D modeling and correlative techniques based on cavity monitoring. Journal of Central South University of Technology, 15(5), pp. 639-644, 2008. doi: http://dx.doi.org/10.1007/s11771-008-0119-3

[3] Wu, Y., The cavity stability numerical simulation based on CMS survey, Master Degree Thesis, Central South University, Changsha, 2007.

[4] Liu, X., Luo, Z., Yang, B., Lu, G., Cao, S. \& Jiang, X., Visible calculation of mining index based on stope 3D surveying and block modeling. International Journal of Mining Science and Technology, 22(2), pp. 139-144, 2012. doi: http://dx.doi.org/10.1016/j. ijmst.2011.08.001

[5] Maerz, N., Assebaum, T.K., Williams, D., Shea, K., Xi, Y., Li, X. \& Duan, Y., Visualizing and modeling interior spaces of dangerous structures using Lidar. International Journal of Safety and Security Engineering, 2(4), pp. 330-350, 2012. doi: http://dx.doi. org/10.2495/SAFE-V2-N4-330-350

[6] Wu, Q., Xu, H. \& Zou, X., An effective method for 3D geological modeling with multisource data integration. Computers \& Geosciences, 31, pp. 35-43, 2005. doi: http:// dx.doi.org/10.1016/j.cageo.2004.09.005

[7] Zeng, P., Finite Element Analysis and Applications. Tsinghua University Press: Beijing, pp. 101-214, 2004.

[8] Bakun-Mazor, D., Hatzor, Y.H. \& Dershowitz, W.S., Modeling mechanical layering effects on stability of underground openings in jointed sedimentary rocks. International Journal of Rock Mechanics and Mining Sciences, 46(2), pp. 262-271, 2009. doi: http:// dx.doi.org/10.1016/j.ijrmms.2008.04.001

[9] Prusek, S. \& Bock, S., Assessment of rock mass stresses and deformations around mine workings based on three-dimensional numerical modelling. Archives of Mining Sciences, 53(3), pp. 349-360, 2008.

[10] Latha, G.M. \& Garaga, A., Elasto-plastic analysis of jointed rocks using discrete continuum and equivalent continuum approaches. International Journal of Rock Mechanics and Mining Sciences, 53(7), pp. 56-63, 2012. doi: http://dx.doi.org/10.1016/j. ijrmms.2012.03.013

[11] Arosio, D., Longoni, L., Papini, M. \& Zanzi, L., Seismic characterization of an abandoned mine site. ACTA Geophysica, 61(3), pp. 611-623, 2013. doi: http://dx.doi. org/10.2478/s11600-012-0090-0 